\title{
Dexamethasone treatment during ventilator dependency: possible life threatening gastrointestinal complications
}

\author{
Elizabeth A O'Neil, Walter J Chwals, Michael D O'Shea, Charles S Turner
}

\begin{abstract}
Corticosteroids in high doses have been used effectively to decrease the duration of ventilator dependency in very low birthweight infants at risk for chronic lung disease. Randomised prospective studies have shown benefit, with only minimal complications being reported. However, review of our experience over 2.5 years with high dose steroids in $\mathbf{8 0}$ premature neonates yielded three major complications: one case each of perforated duodenal ulcer, perforated gastric ulcer, and upper gastrointestinal haemorrhage. Two of the three patients died.

Thus the use of steroids in neonates may not be without risk, and significant complications can occur. When high dose corticosteroids are to be used in very low birthweight neonates, $\mathrm{H}_{2}$ receptor antagonist treatment and gastric $\mathrm{pH}$ monitoring are recommended. The physician must remain alert to the possibilities of upper gastrointestinal bleeding and ulcer perforation in these patients.
\end{abstract}

High dose steroids have been used frequently in the management of ventilator dependent premature infants. Several studies have shown that such treatment accelerates weaning from assisted ventilation and improves pulmonary compliance, and the reported complication rates have been low. ${ }^{1-5}$ Over a 2.5 year period, we have treated 80 ventilator dependent infants with high doses of dexamethasone. Among these infants three have had major complications associated with steroid usage: a perforated duodenal ulcer, a perforated gastric ulcer, and an upper gastrointestinal haemorrhage. Two infants died, resulting in a mortality of $66 \%$. In contrast to the experience of others, then, our experience suggests that significant complications can occur when dexamethasone is used in infants at risk for bronchopulmonary dysplasia.

Dexamethasone is a synthetic steroid having a Department of Surgery Sciences, Bowman Gray School of Medicine of Wake Forest University, Medical Center Boulevard, Winston-Salem, North Carolina, 27157-1095, USA Elizabeth A O'Neil Walter J Chwals Charles S Turner

Department of Pediatrics Michael D O'Shea

Correspondence to: Dr Chwals.

Accepted 11 September 1991 glucocorticoid effect about 30 times more potent than endogenous cortisol. ${ }^{6}$ Most protocols start dexamethasone at an initial dose of 0.5 $\mathrm{mg} / \mathrm{kg} /$ day given either enterally or parenterally. ${ }^{1-5}$ The patient is weaned from the dexamethasone on all protocols, but the times and rates vary. At our institution we use the dexamethasone protocol described by Cummings et al: initial treatment with a dose of 0.5 $\mathrm{mg} / \mathrm{kg} / \mathrm{day}$, which is decreased to $0.3 \mathrm{mg} / \mathrm{kg} /$ day after three days, and thereafter reduced by $10 \%$ every three days until $0.1 \mathrm{mg} / \mathrm{kg} /$ day is reached. ${ }^{5}$ At that point, the drug is given every other day until day 42. The dosage is not changed in the presence of sepsis. Body weight, blood pressure, blood glucose values, and triglyceride concentrations are monitored.

\section{Case reports}

CASE 1

A girl weighing $700 \mathrm{~g}$ born after 25 weeks' gestation was immediately intubated for respiratory distress. After 3.5 weeks of mechanical ventilation, high dose intravenous dexamethasone treatment $(0.5 \mathrm{mg} / \mathrm{kg} / \mathrm{day})$ was begun. On the fourth day of steroid treatment at that dose she developed hypoxia, tachycardia, and abdominal distention; an abdominal radiograph showed free intraperitoneal air. Enteral feeding had not been initiated. At exploratory surgery, a perforated duodenal ulcer was found and repaired. Before $\mathrm{H}_{2}$ receptor antagonist treatment was started, her gastric $\mathrm{pH}$ was $1 \cdot 7$ and her non-fasting serum gastrin concentration was $224 \mathrm{ng} / \mathrm{l}$ (normal range for non-fasting serum gastrin in infants: $100-225 \mathrm{ng} / \mathrm{l}^{7}$ ).

The postoperative course was otherwise uneventful. She was weaned from steroid treatment over several days and extubated on postoperative day 7 .

\section{CASE 2}

A boy weighing $860 \mathrm{~g}$ born after 28 weeks' gestation was intubated immediately and remained ventilator dependent for three weeks. High dose intravenous dexamethasone $(0.5$ $\mathrm{mg} / \mathrm{kg} / \mathrm{day}$ ) was begun, and 10 days later free intraperitoneal air was seen on a routine chest radiograph. The dexamethasone dose at this point was $0.2 \mathrm{mg} / \mathrm{kg} /$ day. At operation, a perforated ulcer was found on the lesser curvature of the stomach proximal to the pylorus. During repair of the ulcer the patient became hypotensive and died.

CASE 3

A boy weighing $900 \mathrm{~g}$ was born after 29 weeks' gestation. After 16 days of ventilator dependency, high dose intravenous dexamethasone $(0.5 \mathrm{mg} / \mathrm{kg} /$ day) was begun. Two days later he developed copious bright red nasogastric drainage and guaiac positive stools. Despite aggressive treatment, including blood transfusions and an $\mathrm{H}_{2}$ receptor antagonist, gastrointestinal haemorrhage persisted and he died five days after the start of steroid treatment. The dexamethasone dose at the time of death was 0.08 $\mathrm{mg} / \mathrm{kg} / \mathrm{day}$. No postmortem examination was performed. 


\section{Discussion}

All three patients from our series were low birthweight premature neonates. All developed severe clinical complications after a short course of high dose steroid treatment. A single perforated ulcer was found in two patients; the third patient had significant upper gastrointestinal haemorrhage. These findings agree with the observation of Grosfeld $e t$ al that acute peptic ulceration in infants tends to be solitary ${ }^{8}$ and with the finding of Tolia and Dubois that peptic ulceration in neonates tends to present as free intraperitoneal air and severe clinical deterioration. ${ }^{9}$

The complications associated with high dose dexamethasone treatment reported from several prospective studies have been minimal, however. Harkavy et al reported hyperglycaemia as the only complication in a group of neonates treated with high dose dexamethasone for a minimum of two weeks. ${ }^{2}$ Gladstone $e t a l^{1}$ and Kazzi et $a l^{4}$ reported no complications in their high dose steroid treated neonates after five days and 17 days, respectively. Cummings et al noted no important gastrointestinal bleeding in their treatment group; however, the control group had a higher incidence of guaiac positive gastric aspirates. ${ }^{5}$ Finally, Alkalay et al noted that four of 10 infants being given high dose steroids developed mild gastrointestinal haemorrhage, which responded to antacid treatment and/or cessation of enteral feedings. ${ }^{3}$ Their steroid protocol was similar to that used at our institution.

Several cases of peptic ulceration and its complications had been reported before the high dose steroid protocol became popular. Grosfeld et al reported a 17 day old neonate who developed a perforated duodenal ulcer while being given steroids for idiopathic thrombocytopenic purpura. ${ }^{8}$ That patient was also treated surgically for a bleeding duodenal ulcer during the same hospitalisation. Chhattriwalla et al reported two premature infants being given steroids for pulmonary deterioration who developed upper gastrointestinal haemorrhage. ${ }^{10}$ In neither of these reports was the steroid dosage specified.

There is still controversy over the ulcerogenic potential of steroid treatment, and numerous papers support each side of the controversy. Conn and Blitzer reviewed prospective investigations from 1950 to 1975 and found no statistical difference in the incidence of peptic ulcers in patients treated with steroid versus those treated with placebo. ${ }^{11}$ On the other hand, although acid hypersecretion is rarely observed with acute stress ulceration, ${ }^{8} 12$ steroid treatment may result in decreased mucus secretion, and in the setting of a compromised mucosal barrier, even normal concentrations of acid might be sufficient to cause ulceration.

The common misconception that premature infants cannot make gastric acid ${ }^{13}$ may lead physicians to believe that neonates are at lower risk for the gastrointestinal complications of steroid treatment and that prophylactic antacids are not indicated. It is noteworthy that the patient in case 1 , a 3 week old premature neonate, was found to have a gastric $\mathrm{pH}$ of $1 \cdot 7$ after the diagnosis of a perforated ulcer. Therefore, we believe that prophylactic $\mathrm{H}_{2}$ receptor antagonist treatment may be beneficial for neonates receiving high dose steroids who are not receiving gastric feeding. We do not recommend oral antacids, because clamping the nasogastric tube in the small neonate may predispose to aspiration. We also recommend that gastric $\mathrm{pH}$ be serially monitored in the neonate receiving steroids who is not receiving gastric feedings.

When steroid related complications such as bleeding or perforation do arise we recommend, in addition to appropriate surgical care, that steroid treatment be discontinued, while keeping in mind the possibility of the hypothalamicpituitary-adrenal axis suppression. Our first patient was safely weaned from $0.5 \mathrm{mg} / \mathrm{kg} /$ day of intravenous dexamethasone over a four day period without adverse sequelae.

In summary, as the high dose steroid protocol is used more frequently for treating ventilator dependency in premature infants, the potential for severe complications and possible death must be kept in mind. Because a long term benefit of high dose dexamethasone has not been proved, we suggest, as have others, that further clinical trials be carried out to identify potential complications of high dose dexamethasone before its use becomes standard practice in ventilator dependent neonates at risk for chronic lung disease.

1 Gladstone IM, Ehrenkranz RA, Jacobs HC. Pulmonary function tests and fluid balance in neonates with chronic function tests and fluid balance in neonates with chronic lung disease during

2 Harkavy KL, Scanlon JW, Chowdhry PK, Grylack LJ. Dexamethasone therapy for chronic lung disease in vent lator-and oxygen-dependent infants: a controlled trial. $\mathcal{J}$ Pediatr 1989;115:979-3.

3 Alkalay AL, Pomerance JJ, Puri AR, et al. Hypothalamicpituitary-adrenal axis function in very low birth weight infants treated with dexamethasone. Pediatrics 1990;86: 204-10.

4 Kazzi NJ, Brans YW, Poland RL. Dexamethasone effects on the hospital course of infants with bronchopulmonary dysplasia who are dependent on artificial ventilation. Pediatrics 1990;86:722-7.

5 Cummings JJ, D'Eugenio DB, Gross SJ. A controlled trial of dexamethasone in preterm infants at high risk for bronchodexamethasone in preterm infants at high risk for broncho-

pulmonary dysplasia. $N$ Engl f Med 1989;320:1505-10. North Am 1973;57:1265-76.

7 Sann L, Chayvialle AP, Bremond A, Lambert R. Serum gastrin level in early childhood. Arch Dis Child 1975;50. 782-5.

8 Grosfeld JL, Shipley F, Fitzgerald JF, Ballantine TVN. Acute peptic ulcer in infancy and childhood. Am Surg 1978;44:13-9.

9 Tolia V, Dubois RS. Peptic ulcer disease in children and adolescents. Clin Pediatr (Phila) 1983;22:665-9.

10 Chhattriwalla Y, Colon AR, Scanlon JW. The use of cimetidine in the newborn. Pediatrics 1980;65:301-2.

11 Conn HO, Blitzer BL. Nonassociation of adrenocorticosteroid therapy and peptic ulcer. N Engl f Med 1976;294;473-9.

Menguy R, Masters YF. Effect of cortisone on mucoprotein secretion by gastric antrum of dogs: pathogenesis of steroid ulcer. Surgery 1963;54:19-28.

13 Leung Y-K, Lebenthal E. Gastrointestinal peptides: physiology, ontogeny, and clinical significance. In: Lebenthal E, ed. Human gastroin

14 Avery GB, Randolph JG, Weaver T. Gastric acidity in the first day of life. Pediatrics 1966;37:1005-7. 